\title{
VIDA, HISTORIA Y PSICOLOGÍA EN WILHELM DILTHEY*
}

\section{Luis María Lorenzo ${ }^{* *}$}

Resumen: Heidegger ve en Dilthey la figura del primer filósofo que supo dar cuenta de la vida como fenómeno. En este artículo se indaga en la filosofía de la vida diltheyana con el fin de encontrar el lugar que en ella ocupa la historia, la psicología y el mundo social. Si bien el individuo es el eje del análisis diltheyano, no lo es como un ser aislado, sino como un "punto de cruce»; el hombre deviene un ser histórico como fruto de sus múltiples contactos con el mundo socio-cultural al que pertenece. La psicología hablará del hombre y la historia hará lo propio sobre el mundo socio-cultural, ambas, en conjunto, conforman el vasto campo del que tienen que dar cuenta las Geisteswissenschaften (ciencias del espíritu). La vida humana es la que articula ambos polos del análisis, vida que fue olvidada por la filosofía y que la "filosofía de la vida" (Lebensphilosophie) busca rescatar.

Palabras clave: Vida - Psicología - Historia - Individuo - Sociedad.

Abstract: Heidegger finds in Dilthey the first philosopher who interprets life as a phenomenon. This paper explores Dilthey's philosophy of life trying to evaluate the importance that history, psychology and the social world have in it. The individual is the main focus of Dilthey's analysis but not as an isolated being but as a "crossover point". Men become historical beings as the result of their contact with the social and cultural world. Psychology, studying man, and history, studying the social-cultural world, conform together the vast field of the human sciences o Geisteszissenschaften. Human life is the sphere that articulates both poles of the analysis, assuming that life was forgotten by philosophy and "philosophy of life" (Lebensphilosopbie) tries to give account of it.

${ }^{*}$ El presente artículo fue posible gracias a las reflexiones internas de los grupos de investigación correspondientes tanto al proyecto del CONICET titulado "El presente del pasado: conformación de la conciencia histórica" (PIP 0865) como al proyecto de la Universidad Nacional de General Sarmiento titulado "La filosofía hegeliana de la historia y sus recepciones crítica en el siglo XX".

Profesor en Filosofía por la Universidad Nacional de General Sarmiento. En la actualidad es becario del Conicet y cursa el Doctorado en Filosofía en la Universidad Nacional de La Plata. Dirección electrónica: luism.lorenzo@gmail.com 
Keywords: Life - Psychology - History - Individual - Society

El objetivo del presente trabajo es introducirse en las reflexiones diltheyanas en torno a la psicología explicativa y la psicología descriptiva no con el fin de efectuar una lectura estricta y detallada de ambas, sino a los efectos de mostrar que las objeciones que Dilthey le realiza a la primera y su adhesión a la segunda se encuentran vinculadas a una profunda reflexión en torno a la vida y al individuo, no como ser aislado sino como sujeto vinculado con la trama de lo histórico-social-cultural, un mundo intersubjetivo que impide cualquier acepción solipsista. Este artículo, pues, busca clarificar algunos de los ejes fundamentales en torno a la filosofía diltheyana donde la vida aparece con todas sus fuerzas: vida que en el hombre es espíritu y deviene histórica; vida que se objetiviza y forma instituciones; vida que escapa de su forma primitiva (de la que hablan las ciencias naturales) hacia el campo de la intersubjetividad, lugar propio del hombre.

Como es bien sabido, la psicología es, para Dilthey, uno de los ejes principales para la fundamentación de las ciencias del espíritu; no obstante, como se buscará demostrar en el presente artículo, ella depende de la vida pues es el fenómeno del cual la "filosofía de la vida" (Lebensphilosophie) pretende dar cuenta.

Si bien la psicología es la ciencia que estudia los hechos de la conciencia, entendida como la plena interioridad del yo, Dilthey explora otros caminos para evitar el solipsismo. Heidegger en unas conferencias que impartió en Kassel en 1925 dedicó uno de sus cursos a la obra de Dilthey. En esta conferencia titulada "La investigación de Wilhelm Dilthey y el conflicto presente sobre una histórica "concepción del mundo" sostuvo: 
La meta de ambas direcciones antes nombradas de su investigación ${ }^{1}$ tienen por objeto comprender (Erfassung) y hacer evidente el fenómeno de la vida. Esta búsqueda es la que Dilthey intenta realizar con su psicología y concretamente lo hace a través de una cierta confrontación con la psicología tradicional, donde el sentido propio del ser de la vida pierde su valor. ${ }^{2}$

El acento que Heidegger da a la noción de vida en la filosofía de Dilthey es tal vez su aporte más importante para la comprensión de la obra de este último pues permite desprenderla del marco estrictamente epistemológico. No obstante, es llamativo. que Heidegger detenga allí su indagación sobre la filosofía de Dilthey para comenzar a hablar de su propia filosofía, la cual tomará cuerpo en Ser y tiempo. ${ }^{3}$

1 Heidegger se refiere aquí a las descripciones que realiza en torno a las investigaciones diltheyanas sobre de la posibilidad de una científica-histórica. Aborda en los apartados anteriores de su conferencia de 1925 las direcciones psicológica y epistemológica, tema que retomará luego en Sery tiempo, $\ 77$.

2 „Als Zeil beider Forschungstichtungen zeigt sich also die Erfassung und Sichtbarmachung des Phänomens des Lebens. Das versucht Dilthey nun auch in seiner Psycologie in Angriff zu nehmen, und zwar in einem gewissen Gegensats zur traditionellen Psychologie, in der das eigentümliche Sein des Lebens preisgegeben wird" "“Conferencia de Kassel", del 16 al 21 de abril de 1925, conformada por un total de 10 conferencias. Se toma la cita de la edición bilingüe del francés, Heidegger, M., Les conférences de Cassel, Librairie Philosophique J. Vrin, Paris, 2003, p. 160. Traducción propia).

${ }^{3}$ Cabe remarcar aquí que este descubrimiento del fenómeno de la vida en Dilthey no parece jugar un papel determinante en Heidegger, al menos no en los términos postulados por el primero. Un análisis más acabado sobre el tema se puede encontrar en Ricouer, quien en La memoria, la bistoria y el olvido sostiene que la tematización heideggeriana sobre la muerte es el relato fundador de todas las condiciones de posibilidad del Dasein; en otras palabras, la vida como potencia es reemplazada por la potencialidad del Ser-para-la-muerte. Ricoeur se asombra por el silencio heideggeriano sobre el estadío inaugural del nacimiento y rescata el concepto de natalidad arendtiano: "En ninguna parte, quizás, se hace sentir más vivamente la ausencia de una reflexión sobre la carne que hubiese permitido 
Retomando este descubrimiento dejado de lado por Heidegger, se puede decir que Dilthey pone el énfasis de su estudio en la vida y el sentido como puntos cruciales para poder emprender su labor en torno a las ciencias del espíritu. Analiza la psicología del individuo pero también su obrar, esto es la acepción correcta del término espíritu (Geist). En tal sentido intentaremos mostrar que Vida, fin, valor, sentido y significado se encarnan en las distintas concepciones del mundo; sólo un profundo análisis y una exhaustiva descripción de ellos abrirán la vía de la comprensión y la interpretación. Sólo el análisis sobre el sentido de la vida (Lebensdigkeit) brindará una comprensión cabal de la conciencia histórica del mundo de una época y clarificará la condición humana gracias al nexo estructural de la vida (Strukturzusammenhang des Leben). ${ }^{4}$ Así el hombre deviene un ser histórico y todo acto de comprensión es relativo. ${ }^{5}$

Dilthey busca comprender al hombre desde un análisis de los individuos particulares, su vida y su relación con el mundo socio-cultural (el espíritu objetivo -Objektiv Geist- y las cosmovisiones del mundo -

designar la natalidad como condición de ser ya ahí y no sólo como acontecimiento del nacimiento, falsamente simétrico del aún no advenido de la muerte" (Ricoeur, P. (2000), La memoria, la bistoria y el olvido, Buenos Aires, FCE, 2008, p. 484). Sobre el concepto de natalidad como potencialidad del hombre ver: Arendt, H. (1965), La condición bumana, Trad. Gil Novales, Buenos Aires, Paidos, 2005, pp. 22-3 y 201-2. ${ }^{4}$ Cfr. Ricoeur, P., op. cit., pp. 478ss.

${ }^{5} \mathrm{Al}$ respecto del relativismo cabe recordar que Renato Cristín realiza una muy interesante exposición en torno al tema de la historicidad y la fenomenología poniendo en relación la filosofía diltheyana y la husserliana. En lo que refiere a los objetivos de este trabajo cabe remarcar únicamente su propuesta de lectura de la obra de Dilthey entendiendo su relativismo como relacionismo. Sostiene, "Dilthey elabora una filosofía de la vida en la cual es fundamental la relación entre individuo y mundo" (Cristín, R., Fenomenologia de la historicidad, el problema de la bistoria en Dilthey y Husserl, Akal, Madrid, 2000, p. 78). Cristín concibe dos tipos de relacionismo uno, defendido por él, que lo denomina relativismo relacionista (aplicable a Dilthey) y, otro, relativismo solipsista. El relativismo-relacionista diltheyano no es un realtivismo extremo como el de Protágoras, sino que implica que todo sujeto y todo hecho histórico tiene una verdad relativa a su época y contexto social. En este sentido, no se podría establecer un método en las ciencias del espíritu que conduzca a un saber universal. 
Weltanschaunng- con que se relaciona). El énfasis puesto en la vida (y rescatado por Heidegger) se ve claramente corroborado por la misma pluma de Dilthey quien en su "Prólogo" a la Introducción a las ciencias del espiritu expone claramente cuál es su punto de partida y su objetivo filosófico al escribir:

Por las venas del sujeto conocedor construido por Locke, Hume y Kant no circula sangre verdadera sino la delgada savia de la razón como mera actividad intelectual. Pero mi interés histórico y psicológico por el hombre entero me condujo a colocar a este hombre en la diversidad de todas sus fuerzas ${ }^{6}$.

El trasfondo de este párrafo es de vital importancia para comprender cabalmente la filosofía diltheyana, el sujeto postulado por estos tres filósofos es para Dilthey "mero juego diluido de la razón”, donde se pierde la riqueza de lo humano al postular una Razón dominante. El hombre ya no puede pensarse en abstracto, como un ser racional, sino en su vida concreta y contextual. El "hombre entero" al que hace referencia la cita es el hombre como "punto de cruce". Dilthey coloca al hombre en el mundo como un ser viviente donde actúan las diversa fuerzas de su acción intencionalcognocitiva, pero también las de su vida volitiva-sentimental y las del mundo con que se relaciona (esto es, el querer, el sentir y el representar).

\section{La psicología explicativa y la psicología descriptiva y analítica}

Durante el siglo XVIII y parte del XIX la filosofía, impulsada en parte por una vuelta a Kant y en otra por el desarrollo propio de las ciencias naturales, se transformó en teoría del conocimiento. El trabajo sistemáticonaturalista y el positivismo dejaron a un lado la pregunta por el sentido de la historia y del hombre. La historia y el hombre sólo se conocen y explican, según estas corrientes, desde una filosofía que trabaje como ciencia,

\footnotetext{
'Dilthey, W. (1883), Introducción a las ciencias del espiritu, Trad. E. Imaz, México, FCE, México, 1949, p. 6.
} 
poniendo en este caso su foco en la psicología explicativa. Hacia ella se dirigió uno de los principales cuestionamientos de Dilthey, para quien, al reconocer las limitaciones de la psicología naturalista y al despegarse de ella se podría encontrar el verdadero modo de ser del hombre, su forma de vida en tanto voluntad que actúa con libertad y no sometida a una ley que determine todo su ser. Es necesario clarificar esto de la psicología explicativa y diferenciarla de la descriptiva, sintéticamente, la primera parte de hipótesis y la segunda desemboca en ellas.

La psicología explicativa pretende construir las grandes conexiones permanentes tales como espacio, tiempo y causalidad partiendo de ciertos procesos elementales estudiados por ella, tales como asociación, fusión, apercepción; la psicología descriptiva, por el contrario, separa la descripción y el análisis de estas conexiones permanentes de las hipótesis explicativas ${ }^{7}$.

Toda psicología explicativa se encuentra ligada a un determinado modo de hacer ciencia basados en una filosofía de la naturaleza. En oposición a la metafísica, Galileo propuso un método lógico para la ciencia, un postulado de cómo llegar a formular leyes universales y con las cuales se podían dominar las manifestaciones del mundo. No obstante, al formular sus leyes Galileo no comienza desde una mera observación sino de un postulado o un supuesto general (por ejemplo, el carácter homogéneo y cuantitativo del tiempo), es decir, una hipótesis de puras relaciones matemáticas. A partir de aquí procede desde una deducción puramente formal hasta hacer explícita la formulación de una ley a la cual somete a prueba en la experiencia. Así busca mensurar el mundo, subsumirlo al desenvolvimiento -una dinámica general- de una ley universalmente válida $^{8}$. Algo similar sucede con la matemática newtoniana. Dilthey no

7 Dilthey, W., (1894), "Ideas acerca de una psicología descriptiva y analítica", en Dilthey, W., Psicologia y teoria del conocimiento, Trad. Imaz, FCE, México, 1951, p. 232. ${ }^{8}$ Cfr. Heidegger, M., (1915), "El concepto del tiempo en la ciencia histórica", en Heidegger, M., Tiempo e historia, Trad. Escudero, Trotta, Madrid, 2009, pp. 19ss. 
critica a las ciencias naturales sino a aquellos que pretenden apoderarse de sus desarrollos y llevarlos a un ámbito que le es ajeno, el de la vida psíquica. Someter la actividad del hombre a los designios de la naturaleza es cortarle parte de su propio ser. Recordando a Heidegger, "el tiempo histórico no puede expresarse matemáticamente por medio de una serie, no hay ninguna ley que determine cómo se suceden las épocas" ". No obstante, como se verá, Dilthey no descarta los puntos positivos de los descubrimientos obtenidos por la psicología explicativa; sostiene que todas sus construcciones tendrán un valor heurístico (aunque nunca conducirán a un saber objetivo) sólo cuando marchen por detrás del análisis de una psicología descriptiva ${ }^{10}$.

Según Dilthey, la psicología explicativa nace con el empirismo inglés. Locke sostenía, siguiendo el patrón de las ciencias naturales, que las operaciones lógicas de la conciencia (unir, separar, encontrar igualdades y diferencias) permiten establecer un conocimiento del mundo externo. Por su parte, Hume creía que las leyes de asociación de ideas e impresiones y el desarrollo del hábito originaban el modo en que el hombre accede al conocimiento del mundo ${ }^{11}$. Según la interpretación de Dilthey, Kant fue el primero en rechazar estas psicologías explicativas y postular una descriptiva-naturalista ${ }^{12}$; no obstante su vinculación con las matemáticas condicionaron todos sus desarrollos y lo condujeron a encontrar en el $a$ priori aquellas condiciones de posibilidad subjetivas del conocimiento: fundamentó su teoría a partir de un axioma, por ello sigue operando dentro de la lógica axiomática matemática ${ }^{13}$. Finalmente, el desarrollo de las corrientes empiristas del siglo XVIII determinadas por las leyes de la mecánica psíquica a modo naturalista, donde se encuentran Mill y Comte (con su sociología), buscaron un conocimiento puramente científico -

9 Para Heidegger, el tiempo histórico sólo tiene valor significativo en su dimensión cualitativa y la cronología es una ciencia auxiliar de la historia que posibilita algún tipo de mensurabilidad más bien anecdótica. (Cfr., Ibid., p. 36).

${ }^{10}$ Cfr. Dilthey, W., "Ideas acerca de una psicología descriptiva y analítica", p. 240.

11 Cfr. Dilthey, W. (1898-1903), "En torno a Kant", en Dilthey, W., De Leibniz a Geothe, Trad. Imaz y otros, México, FCE, 1978, p. 328.

12 Cfr., Ibid., pp. 334ss.

13 Cfr., Ibid., pp. 327ss. 
atacando a la metafísica-, no obstante sometieron al hombre y su actuar a las leyes naturales.

Para Dilthey, "[l]a psicología explicativa puede lograr su meta únicamente valiéndose de hipótesis"14. Considera que el concepto de hipótesis puede ser considerado de diversos modos, en líneas generales es una "expectativa" que busca ser llenada con lo dado. El problema de la psicología explicativa es que ha elaborado un concepto restringido de hipótesis, teniendo como base el conocimiento natural y en especial su ley de causalidad. Como en la física de su tiempo, busca obtener un cúmulo de regularidades en base a un conjunto de pre-supuestos tomados como válidos. Para Dilthey no existe en el hombre ni en su mundo esa relación lógica causal que encuentra la ciencia natural en los objetos. El hombre es un ser activo y sus acciones poseen proyecciones y motivaciones, esto es el carácter teleológico de la acción humana que se opone a la homogeneidad de la lógica de la causalidad. Además, la psicología explicativa parece olvidar la diferencia de objetos de estudios, el uso libre de la experimentación y la mensurabilidad que posee la ciencia natural y que no disponen las ciencias del espíritu ${ }^{15}$. Dilthey no rechaza la utilización de hipótesis, más bien dice que sin ellas no puede operar ciencia alguna; sólo busca señalar que la psicología explicativa, la sociología de Comte e incluso la filosofía trascendental de Kant recortan el mundo humano e impiden ver con precisión la complejidad de la actividad humana, la cual sólo se logrará por medio de un profundo análisis y descripción del hombre a través de la psicología y una comprensión total de lo que es el hombre en tanto ser histórico. Para Dilthey, por lo tanto, la psicología debe ser descriptiva y no explicativa, analítica y no constructiva. ${ }^{16}$

${ }^{14}$ Dilthey, W., "Ideas acerca de una psicología descriptiva y analítica", p. 193. ${ }^{15}$ Cfr., ibid., p. 196.

16 "Las ciencias del espíritu se diferencian de las ciencias de la naturaleza, en primer lugar, porque éstas tienen como objeto suyo hechos que se presentan en la conciencia dispersos, procedentes de fuera, como fenómenos, mientras que en las ciencias del espíritu se presentan desde dentro, como realidad, y, originalmente, como una conexión viva. Así resulta que en las ciencias de la naturaleza se nos 
Los diversos desarrollos en el campo de la psicología explicativa condujeron a la postulación de leyes sobre la psicología interna que sirvieron, en alguna medida, para la descripción y el análisis de los hechos psíquicos pero llevaron también, por su subordinación a las ciencias naturales-matemáticas, a una frustrante postulación de leyes deterministas sobre la vida psíquica. La escuela de la psicología explicativa subordina la psicología al conocimiento natural por medio de la hipótesis del paralelismo entre procesos físicos y fisiológicos; postula que ningún fenómeno psíquico se produce si no está acompañado de uno físico ${ }^{17}$. Por ello la psicología explicativa busca descomponer la conciencia en sus elementos básicos; establecer las leyes de su combinación; encontrar para cada contenido psíquico elemental su correlato en un fenómeno físico - del cual deriva-. Todo proyecto de una ciencia psicológica independiente se trunca por su subordinación a la fisiología y al método natural. En consecuencia, Dilthey reclama:

Las ciencias del espíritu tienen necesidad de una psicología que, ante todo, sea firme y segura, cosa de la que no puede ufanarse ninguna de las psicologías explicativas existentes en la actualidad, y que al mismo tiempo someta toda la poderosa realidad de la vida psíquica a la descripción, y, en la medida de lo posible, al análisis. Porque el análisis de la realidad social e histórica, tan compleja, podrá ser llevado a cabo únicamente si esta realidad es desarticulada primero en los diversos sistemas de fines que la componen; estos sistemas o nexos finales, tales como la vida económica, el derecho, el arte y la religión, permiten luego, gracias a su homogeneidad, el análisis de su tramado. Pero este tramado de un sistema semejante no es otra cosa que la conexión psíquica propia de los hombres que cooperan en esos nexos culturales. Se trata, por lo tanto, de una conexión en último término psicológica ${ }^{18}$.

ofrece la conexión natural sólo a través de conclusiones suplementarias, por medio de un haz de hipótesis. Por el contrario, en las ciencias del espíritu tenemos como base la conexión de la vida anímica como algo originalmente dado" (Ibid., p. 197). ${ }_{17}$ Cfr., Ibid., p. 216. ${ }^{18}$ Ibid., p. 208. 
No es este el lugar para profundizarlo, pero es necesario señalar las claves que la cita trae a colación, las cuales se desarrollarán más adelante. Aquí cabe remarcar que ya desde su inicio la psicología diltheyana no busca analizar al individuo aislado sino en contacto con su mundo. Los sistemas de fines, los nexos finales y las tramas son las conexiones psíquicas de los individuos que cooperan intersubjetivamente en su mundo socio-cultural.

Retomando el tema de las hipótesis, es necesario enfatizar que para Dilthey todo abordaje científico sin una teoría supuesta es una ilusión ${ }^{19}$. Afirma, sin embargo, que no se debe creer, como sucedía en su tiempo, que los supuestos esbozados en las hipótesis son válidos en sí mismos y critica a quienes poseen una mirada despierta sólo para aquello que pueda corroborar sus hipótesis y censuran toda vía que conduzca a contradecirlas $^{20}$. La psicología parte de hipótesis, pero no se debe postular que la vida psíquica puede ser explicada a través de determinaciones tan exactas como lo son las leyes naturales de la necesidad. Dilthey denuncia ya en 1894 el uso deductivo de las hipótesis y busca que ellas, a la manera de los tipos ideales weberianos, se conviertan en una expectativa a cumplir, una guía -un medio- para la investigación y no un postulado axiomático al que la realidad deba adecuarse. La expectativa de una hipótesis podrá cumplirse pues las regularidades en la vida psíquica se producen gracias a su actividad teleológica, la cual no puede subordinarse a ley natural alguna. Por ello, la psicología debe descomponer la actividad de la conciencia, no buscar la génesis de la conciencia; encontrar esas regularidades requiere comprender que la configuración de la conciencia está ahí en la trama del mundo sociocultural, no se constituye a partir de elementos formales genéticamente detectables sino de estructuras adquiridas. Estas son las experiencias que tiene el hombre de sí mismo a partir del contacto con el mundo; en ellas se relacionan el yo y el mundo, vida vivida en común, en el despliegue de la libertad, el desarrollo y la historia; la estructura psíquica es también heredada -adquirida-, pues es vida vivida con el otro. El hombre como ser viviente se sitúa entre diversas fuerzas intencionales y sentimentales

${ }^{19}$ Cfr., Ibid., p. 203.
${ }^{20}$ Cfr., Ibid., p. 198. 
(reflejadas en la estructura tripartita del querer, el sentir y el representar) que actúan configurando el mundo humano.

Si bien utiliza hipótesis, la nueva psicología debe partir de un punto diferente de aquella psicología de método constructivo-naturalista (como aquel conjunto de pasos o instrucciones que permiten calcular la solución de un problema dentro de un límite determinado de casos), su marcha ha de ser analítica: debe partir de la vida anímica desarrollada, evitar los prejuicios (hipótesis deterministas) y no tratar de derivarla partiendo de procesos genéticamente elementales. Dilthey reconoce que la síntesis, la deducción y la inducción condicionan todo conocimiento, pero para evitar los excesos toda psicología debe analizar, describir y comparar al hombre desarrollado y la vida psíquica completa y acabada (la vivencia y la expresión), en búsqueda de una comprensión (Versteben) lo más objetiva posible.

El concepto de una psicología descriptiva y analítica surgió en nosotros de la naturaleza de nuestras vivencias psíquicas, de la necesidad de una captación intacta y sin prejuicios de la vida anímica, así como de la conexión de las ciencias del espíritu y de la función de la psicología dentro de las mismas. Por lo tanto, sus propiedades tendrán que derivar de estos motivos (...) Esta misión reclama dos cosas. Por un lado, hay que exponer la realidad íntegra de la vida psíquica y, en lo posible, analizarla, y por otro, esta descripción y análisis habrán de poseer el grado máximo de seguridad que se pueda lograr ${ }^{21}$.

En síntesis, la psicología explicativa se encuentra atada al mundo natural y al abordaje nomológico-deductivo de las ciencias naturales (modelo explicativo-Erklären-); por tanto, a un mundo que remite a una realidad distinta de la propiamente humana. Esto no quiere decir que el hombre nada tenga que ver con el mundo natural, sino que éste no expresa su especificidad. La psicología descriptiva, según la entiende Dilthey, se ocupa en cambio de los individuos históricos y de los procesos históricos

${ }^{21}$ Ibid., p. 219. 
como manifestaciones de la vida (Leben), vivencia (Erlebnis) y expresión (Ausdruck), captables desde el modelo analítico-descriptivo de la comprensión (Verstehen). Este nexo efectivo se distingue de la conexión causal de la naturaleza porque, a tenor de la estructura de la vida anímica, engendra valores y realiza fines (el carácter teleológico-inmanente del nexo efectivo espiritual). La vida histórica es creadora; se halla constantemente ocupada en la producción de bienes y valores, y todos los conceptos referentes a estos términos no son más que reflejos de semejante actividad $^{22}$.

\section{El individuo como el agente del mundo espiritual.}

La época de Dilthey se ve atravesada por el retorno a Kant iniciado por el neo-kantismo que buscaba en el sujeto trascendental la fundamentación gnoseológica que se había perdido con la irrupción del positivismo. Entre sus corrientes más importantes encontramos la "escuela de Marburgo" y la "escuela de Baden". La primera, también conocida como "corriente lógico-metodológica" centrada en la doctrina del método trascendental -entendido como condición de posibilidad-, estableció como punto de partida la experiencia científica, tal como se presenta en las ciencias físico-matemáticas; entre los representantes de esta escuela se pueden nombrar a Cohen y Natorp, a los que se sumaron luego Karl Vorländer y Ernst Cassirer. La segunda, la "escuela de Baden" o del "neokantismo axiológico", sostuvo que el fundamento último de toda filosofía es "ética del pensar"; en tal sentido, sus representantes más destacados -Windelband y Rickert, claramente influenciados por Diltheyasumieron el kantismo como una filosofía de la cultura y no una teoría del conocimiento ${ }^{23}$.

22 Cfr. Dilthey, W., (1905-1910), "Estructura del mundo histórico por las ciencias del espíritu”, en Dilthey, W., El mundo bistórico, Trad. Imaz, México, FCE, 1944, p. 178.

${ }^{23}$ Cfr. Caimi, M., "La tradición kantiana”, en Villacañas, J., La filosofía del siglo XIX, Enciclopedia Iberoamericana de Filosofia, Vol. 23, Madrid, Trotta, 2001. 
Dilthey describe su época como una pugna de modelos donde, por un lado, el retorno a la gnoseología de Kant permitía volver a la interioridad humana y su independencia, pero obturaba la existencia del objeto exterior del que tenía que dar cuenta la ciencia. Por el otro lado, se encontraba el positivismo que, posado sobre el mundo natural, negaba la independencia de la interioridad humana ${ }^{24}$. Esta temática se encuentra muy claramente expuesta en su Introducción a las ciencias del espiritu. Allí sostiene que si el científico parte de la percepción interna se abocará al mundo de la conciencia (como ocurre en Hume y Kant), postulando un sujeto del que todo depende; si por el contrario parte de la captación sensible hablará de lo material (como es el caso de Comte), postulando una naturaleza objetiva que determina al sujeto -recortando su libertad-. Ambos puntos de vista sólo refieren al plano de la experiencia (Erfabrung), mas las ciencias del espíritu se refieren a la "experiencia de la vida" (Lebenserfabrung), al mundo humano, a la vida vivida y la vivencia (Erlebnis). Esta escisión del mundo interno y externo imposibilita comprender (versteben) la vida. Ella es un sistema de relaciones donde cada ciencia que busca conocerla o comprenderla tiene una autonomía relativa ${ }^{25}$, aunque esto no implica que entre el conocimiento natural y la comprensión del mundo espiritual se de una estructura lógica de análisis análoga ${ }^{26}$. Desde estas posiciones enfrentadas no se podía comprender al hombre y su mundo; ambos no resuelven la problemática de las ciencias del espiritı. Dicha problemática sólo se resolverá cuando se aborde la pregunta por la posibilidad de un conocimiento objetivo en las ciencias del espíritu ${ }^{27}$. Dilthey especifica el problema, al agregar que "[e]n este planteamiento del problema entra, como supuesto, un concepto de la Historia. Ya vimos que este concepto depende

\footnotetext{
${ }^{24}$ Esto se expuso en el punto anterior, cuando se habló de la psicología explicativa.

${ }^{25} \mathrm{Cfr}$. Dilthey, W., Introducción a las ciencias del espiritu, p. 32.

${ }^{26}$ Cfr., Ibid., pp. 24-6.

27 Cfr. Dilthey, W., (1905-1910), "Estructura del mundo histórico por las ciencias del espíritu”, en Dilthey, W., El mundo bistórico, p. 286.
} 
del de la vida. Vida histórica es una parte de la vida general. Pero ésta es lo que 'se da' en la vivencia y en el comprender" 28 .

Aquí aparece la vida con todas sus fuerzas. ¿Qué significa que la historia es parte de la vida general? Se podría dar dos respuestas a esta pregunta, una que entienda por vida histórica aquella que refiere a la vida humana en común - vida intersubjetiva- y por vida general la vida natural de la cual es parte; otra, que dentro del mundo humano, entienda por vida general la vida en común -vida objetiva, espíritu objetivo- y por vida histórica al valor puesto en el individuo. En ambos casos el individuo es el único ser actuante y la historia es el nexo de sentidos dados por la interacción de individuos. En estos nexos Dilthey no encuentra determinación alguna sino tan solo innovación, el individuo es el único ser creador de su realidad.

Esta preocupación de Dilthey puede comprenderse también a partir de los procesos de la Alemania de su tiempo. En su época el segundo Reich se encontraba en proceso de aumentar sus fuerzas y alcances hasta el punto de que el individuo se veía subsumido al Estado ${ }^{29}$. En este contexto, Dilthey reclama que el individuo retome su valor propio y se muestre como el autor de lo social, un agente, un ser actuante. En otras palabras, Dilthey quería mostrar que el Estado no es un ser absoluto de derecho, por lo cual el individuo tampoco es su instrumento; el mundo social es el lugar donde actúan seres libres y producen en sus expresiones y su historia las objetivaciones humanas. ${ }^{30}$ Esto explica, en parte, el rechazo diltheyano al "espíritu absoluto" hegeliano y su incorporación al "espíritu objetivo". Los sucesos bélicos de la Alemania, en especial la Primer Guerra Mundial y la República de Weimar, parecen justificar dicho reclamo ${ }^{31}$. Al caer ese gran Estado los individuos sometidos al segundo Reich se quedaron huérfanos, carentes de vida, sin rumbo y sin sentido; esto también permitiría

\footnotetext{
28 Ibid., p. 286.

29 Para Villacañas, éste es el paradigma del Estado hegeliano. Cfr. Villacañas, J., Historia de la filosofía contemporánea, Akal, Madrid, 2001.

${ }^{30}$ Cfr., Ibid., p. 125.

${ }^{31}$ Cfr., Ibidem.
} 
comprender, en parte, la aparición del totalitarismo como quien vuelve a otorgarle al Estado y al mundo su sentido perdido.

Volviendo al análisis propiamente filosófico, para Dilthey comprender el mundo histórico y social no es conocer sus leyes a modo cientificista, ni conocer la interioridad del individuo (recuérdese el principio Individuum est ineffabile de Schleirmacher que retoma Dilthey ${ }^{32}$ ), sino adentrarse en el mundo de sentidos producido por el individuo en su relación con otros individuos y con las distintas objetivaciones de la vida todo esto constituye aquello que Dilthey denomina "expresión" (Ausdruck). Para Dilthey las ciencias del espíritu surgen en el momento que el hombre toma conciencia de su propia actividad como dotadora de sentidos. Por ello, en su Introducción a las ciencias del espíritu sostiene que el individuo es un todo, una unidad psicofísica, encerrada en si misma y abierta al mundo ${ }^{33}$. En el primer caso se encuentra encerrado en sus propias representaciones del mundo y sólo tiene autoconciencia de su unidad; en el segundo amplia su autoconciencia al establecer nexos -engarzarse dirá más tarde Ricoeur-con la trama socio-histórica. Lo que hace la psicología es en un primer momento extraer al individuo de su trama socio-histórica para comprenderlo desde su interioridad; analiza y describe sus características. Pero esta interioridad no es producida en aislamiento ni se puede abarcar completamente por el principio antedicho. Por ello, para lograr una comprensión cabal del individuo siempre se ha de recordar que todo análisis debe volver a colocarlo en su conexión original dotadora de sentido, su trama y sus estructuras adquiridas ${ }^{34}$. "El hombre, como hecho que

${ }^{32}$ Cfr. Dilthey, W., (hacia 1910), "Orígenes de la hermenéutica”, en Dilthey, W., El mundo bistórico, p. 335.

${ }^{33} \mathrm{Cfr}$. Dilthey, W., Introducción a las ciencias del espiritu, pp. 39ss.

${ }^{34} \mathrm{~A}$ modo informativo, pues excede el marco del presente artículo, cabe recordar que este modelo de la comprensión es entendido por Ricoeur como un modelo psicológico que busca introducirse en el autor de la acción y reproduce un subjetivismo que mantiene en una constante tensión el problema de la objetividad. No obstante, siguiendo a Gadamer, Ricoeur reconoce en el "espíritu objetivo" ese intento de Dilthey por superar las limitaciones de su propio modelo (Cfr. Ricoeur, P., "La tarea de la hermenéutica desde Schleiermacher y desde Dilthey", en Del 
precedería a la historia y a la sociedad, es una ficción de la explicación genética; el hombre que la sana ciencia analítica tiene como objeto es el individuo como elemento componente de la sociedad" 35 .

La psicología debe ampliar su campo a las acciones prácticas del hombre. Esto refiere a la relación hermenéutica del todo y las partes: siempre se comienza por lo general, lo común a todos y se busca lo particular, lo que hace al sujeto diferente a otros; esta relación del todoparte no es una subordinación de la parte al todo, sino el modo de marcar una relación ineludible. El sentido del mundo humano sólo se logra en el momento en que el hombre se concibe como generador de sus relaciones, cuando sus acciones internas y su actividad práctica entran en contacto con otros hombres y con las formaciones significativas de lo histórico-social. Este es la acepción y el alcance, que se tratará en el apartado siguiente, del hombre como puinto de cruce.

El hombre se encuentra como productor de sentido y al replegarse en su actividad y la de su mundo se hace transparente y se puede comprender. La actividad libre y creadora de la vida humana y los acontecimientos históricos, esto es, el individuo y sus objetivaciones -la expresión y la vida objetivada- son los objetos de estudios de las ciencias del espíritu; no obstante, la fundamentación final de estas ciencias se logrará

texto a la acción, Buenos Aires, FCE, 2010, pp. 78-82). En contrapartida, dentro de su propio modelo dialéctico entre el explicar y el comprender, Ricoeur propone el modelo del texto como aquel que permite encontrar cierta objetividad al distanciarse de la intencionalidad del autor que lo produjo. En este contexto muestra tanto el carácter psicológico de la comprensión que apunta a la reproducción (Nacbbildung) de las vivencias como las limitaciones del modelo estructuralista que entiende al texto como una unidad cerrada con un ordenamiento propio de cadenas relacionales que permiten una explicación autónomamente (Cfr. Ricoeur, P., “¿Qué es un texto?", en Del texto a la acción). El modelo del texto propuesto por Ricoeur consiste en una reconciliación de ambos dentro de una semántica profunda que apunte a las referencias no ostensivas, a las manifestaciones de un Welt que no es Umwelt (Cfr. Ricoeur, P., "El modelo del texto: la acción significativa considerada como texto", Del texto a la acción., p. 193-4). ${ }^{35}$ Dilthey, W., Introducción a las ciencias del espiritu, pp. 40-41. 
cuando el hombre se pregunte por las condiciones de posibilidad de la historia. Cabe recordar que para Dilthey el Espíritu es un ser histórico; "Pero el espíritu es un ser histórico, es decir, que se halla colmado del recuerdo de todo el género humano, que vive en él en abreviaturas, y puede estar lleno de ese recuerdo porque él mismo lo ha engendrado"36. Por ello critica a Kant cuando concibe al espíritu como "sujeto trascendental", lo que lo conduce a no comprender el carácter histórico del hombre, someter a la historia a la idea de progreso, a un ideal de la razón, una historia universal ${ }^{37}$. Kant no interroga la historia sino que propone una sistematización objetivo-teleológica, una estructura independiente de las intenciones subjetivas del hombre, una secularización del plan divino ${ }^{38}$.

Criticar a la psicología explicativa implica que la nueva psicología deberá encontrar sus leyes fundamentales, leyes que tendrán que diferenciarse de los pre-juicios de la vieja psicología que buscaba someter al individuo y a la sociedad a hipótesis axiomáticas; así, la nueva psicología se encaminará hacia la detección de los aspectos básicos de la actividad

${ }^{36}$ Dilthey, W., "Estructura del mundo histórico por las ciencias del espíritu”, p. 303.

37 “El curso histórico es [para Kant] un miembro de la gran conexión natural, pero ésta, a partir de la presencia de los organismos, no puede ser sometida a un conocimiento de su orden según las leyes causales, sino que es accesible únicamente a la consideración teleológica. Así niega Kant la posibilidad de encontrar leyes causales en la sociedad y en la historia y trata, por el contrario, de poner en relación la meta del progreso, tal como la había fijado la Ilustración en la perfección, en la felicidad, en el desarrollo de nuestras capacidades, de nuestra razón, de la cultura en general, con el a priori de la ley moral, estableciendo así, a priori, el sentido y la significación de la conexión teleológica. (...) La consideración teleológica de la historia como el progreso en el desarrollo de aquellas disposiciones naturales que se encaminan al uso de la razón, el señorío de las mismas en una sociedad que practica el derecho de una manera general, el acceso a una "constitución civil perfectamente justa" como la "tarea máxima que la naturaleza ha impuesto a la especie humana", he aquí el hilo conductor a priori por el que se puede explicar el juego, tan confuso, de las cosas humanas" (Ibid., pp. 128-9).

${ }^{38}$ Cfr. Reyes Mate, Por los campos de exterminio, Barcelona, Anthropos, 2003, pp. 127 128. 
psíquica pero no hacia su génesis-. Estas leyes básicas - no deterministas ni axiomáticas- son, a) de la conexión estructural: tiene que ocuparse de la "articulación arquitectónica del edificio concluido, se ocupa de la conexión interna de las partes" 39 . La tarea de la psicología descriptiva y analítica en este plano será encontrar la "ley estructural" que traba la tridimensionalidad de la actividad psíquica: la inteligencia, la vida impulsiva y afectiva y las acciones afectivas - esto es, el representar, el querer y el sentir que Dilthey toma de Kant- con un carácter teleológico-causal; b) de la ley del desarrollo (que nada tiene que ver con el evolucionismo cientificista): consiste en la adecuación a un fin o una conexión de valor que está dado en el nexo estructural no como un juego de una voluntad ciega (átomo de fuerzas psíquicas, como postula Schopenhauer) ${ }^{40}$. El desarrollo consiste en la tendencia del hombre a formar conexiones firmes - estructurales- de la vida psíquica; c) de la conexión adquirida de la vida psíquica: todo acto singular de la conciencia es producto de un juego de relaciones, de fuerzas e intereses de un individuo en contacto con otros y con su mundo; esto es el nexo estructural de la vida psíquica (Struckturqusammenhang).

De este modo se puede comprender las ciencias del espíritu como aquellas ciencias donde lo humano se arraiga como lo espiritual intersubjetivo (a diferencia de las ciencias naturales que someten lo humano a lo físico captable en la percepción y el conocer). Las relaciones entre la vivencia (Erlebnis), la expresión (Ausdruck) y la comprensión ( Verstehen) tienen como sustento a la vida misma y al sujeto histórico. El hombre como punto de cruce es aquel sujeto histórico que se constituye en relaciones intersubjetivas dadas dentro de las estructuras de un mundo compartido $^{41}$.

${ }^{39}$ Cfr. Dilthey, W., "Ideas acerca de una psicología descriptiva y analítica”, p. 225. ${ }^{40}$ Cfr., Ibid., p. 226.

${ }^{41}$ Para Dilthey el término "espíritu" (Geist) abordado por las ciencias del espíritu abarca "el espíritu de las leyes" de Montesquieu, "el Espíritu Objetivo" de Hegel y "el espíritu del derecho romano" de Ihering (cfr. Dilthey, W., "Estructura del mundo histórico por las ciencias del espíritu", p. 106). Al respecto, Ricoeur sostiene que Dilthey pone a la vida como el hogar del espíritu, por lo cual sería 
En relación con el mundo adquiere el hombre sus conexiones psíquicas. Este mundo es vida antes que concepto. Sólo el esclarecimiento de estas relaciones dará luz a la libre vivacidad de la vida psíquica, donde siempre se agitarán los impulsos y los efectos y diferentes grados de atención sobre ellos; desde allí surgen nuestras representaciones y direcciones de la voluntad. Los procesos psíquicos se articulan dentro de la estructura adquirida de la tridimensionalidad de la vida psíquica constituida por lo cognitivo, lo volitivo y lo sentimental-. La vivencia es el modo de acceso inmediato a estos procesos, pero es sólo su percatación. Dilthey hace un llamamiento a no olvidar la vida y la vida vivida como el fundamento del que todo parte pero deja en claro que sólo accedemos a ella por mediaciones. La inmediatez no se da como un todo a la conciencia pues sólo podemos captar la vida psíquica de modo mediato en las acciones o reproducciones psíquicas (la expresión - Ausdruck-). Por eso Dilthey apela a la comparación de las creaciones de la conciencia, de las acciones humanas y de sus objetivaciones para captarlas de modo más completo. Esto es la "expresión" de la vida psíquica que es captada como una forma de la actividad espiritual; esto es el hombre histórico y el espíritu objetivo.

En el lenguaje, en el mito, en las prácticas religiosas, en las costumbres, en el derecho y en la organización exterior tenemos otras tantas producciones del espíritu colectivo en las que la conciencia humana, para hablar en términos de Hegel, se ha hecho objetiva y es apta, por lo tanto, para el análisis. Lo que el hombre es no se conoce mediante la cavilación sobre uno mismo ni tampoco mediante experimentos psicológicos, sino mediante la Historia. Pero este análisis de los productos del espíritu humano que nos permite atisbar el origen de la conexión psíquica, sus formas y su acción, el análisis de los productos históricos habrá de combinarlo con la observación y recopilación de todo fragmento accesible del proceso histórico en el que se forma tal conexión. Precisamente es la unión de estos dos métodos [el histórico y

posible decir con él que la "vida aprehende aquí la vida". Con ello Dilthey pone al idealismo especulativo como base de su filosofía. (Cfr. Ricoeur, P., "La tarea de la hermenéutica desde Schleiermacher y desde Dilthey", en Del texto a la acción, p. 82). 
el descriptivo-analítico] reposa todo el estudio histórico acerca del origen, las formas y la acción de la conexión psíquica en el hombre ${ }^{42}$.

La cavilación sobre uno mismo es la expresión diltheyana para hacer referencia a la reflexión como camino para conocerse a uno mismo. La rechaza porque la asimila a la contemplación de sí -la introspección-, un acto de abstracción que recorta la vivacidad de la vida humana, un encierro en sí mismo. Para Dilthey el hombre sólo se comprende en las mediaciones históricas, en el transcurso de sus acciones en el tiempo, en el análisis, la descripción y la comparación de sus expresiones.

\section{El individuo (espíritu subjetivo) y sus objetivaciones (espíritu objetivo).}

Se ha nombrado al hombre como «punto de cruce» y éste es el momento de profundizar en tal concepción. La misma refleja esa íntima conexión de lo individual y lo plural, la clásica relación hermenéutica del todo y las partes. En cartas personales de su juventud, en 1860, Dilthey postula esta íntima relación entre individuo y cultura (yo-tú-mundo) ${ }^{43}$ y en 1875 sostiene: "El individuo es, al mismo tiempo, un elemento en las interacciones de la sociedad, un punto de cruce de los diversos sistemas de estas interacciones, reacciona con una dirección volitiva y con una acción consciente sobre los efectos de la misma y, por otra parte, es una inteligencia contempladora, investigadora" 44 .

42 Dilthey, W., "Ideas acerca de una psicología descriptiva y analítica", p. 230.

${ }^{43}$ Esto da por tierra con esas clásicas concepciones de Dilthey como psicologista que cae en un solipsismo, o de dos etapas de su pensamiento, una psicologista y otra herméneutica. La preocupación por el hombre, en tanto individuo, y por su mundo, en tanto lugar de la intersubjetividad, donde el mundo ya no es mera representación sino el lugar de acción de la Vida humana, está en Dilthey desde temprana edad y recorre todas sus reflexiones y pensamientos.

${ }^{44}$ Dilthey, W., (1875), "Acerca del estudio de la historia de las ciencias del hombre, de la sociedad y del estado", en Psicologia y teoría del conocimiento, p. 401. El subrayado es mío. 
Esa acepción del "hombre como punto de cruce" aparece nuevamente en su Introducción a las ciencias del Espíritu; allí sostiene

El individuo es (...) un elemento de la interacción de la sociedad, un punto de cruce de los diferentes sistemas de interacciones, que reacciona con una voluntad consciente y con la acción sobre la influencia de esos sistemas y que es, al mismo tiempo, la inteligencia que contempla todo esto y lo investiga. ${ }^{45}$

Vuelve a postular esta relación entre los individuos y sus sistemas culturales en un artículo que data entre 1905 y 1910. Allí, en un claro gesto por de diferenciarse de Hegel, destaca a los individuos como soporte de los sistemas culturales. El hombre -creador de sus producciones, sus objetivaciones de la vida, ser contemplador y enjuiciador- es generador de sus fines y valores, por tanto éstos no vienen impuestos producto del devenir de la Idea. Asimismo estas objetivaciones de la vida, como su núcleo es el hombre, pueden ser captadas psicológicamente. En otros términos, los "nexos efectivos" necesitan un "nexo estructural" (Zusammenhang). Éstos se constituyen primariamente en los individuos, pero, en tanto los mismos son "puntos de cruce", también los adquieren; cabe aclarar que igualmente son "puntos de cruce" las comunidades, naciones y sistemas culturales. "Como el individuo, así también todo sistema cultural, toda comunidad, tiene un centro en sí misma. En ellos la captación de la realidad, la estimación de valores, la producción de bienes se enlazan en un todo" 46 . No obstante, este centrarse en sí mismo, no es reflexivo sino histórico. "Los diversos soportes de la creación se hallan entrelazados en conexiones histórico-sociales más amplias; así, tenemos las naciones, las épocas, los períodos históricos. Así surgen formas más

\footnotetext{
${ }^{45}$ Dilthey, W., Introducción a las ciencias del espiritu, (Op. cit.), pp. 45-6. El subrayado es mío.

${ }^{46}$ Dilthey, W., "Estructura del mundo histórico por las ciencias del espíritu", en El mundo bistórico, p. 178-9.
} 
complicadas del nexo histórico" 47 . El hombre es un ser histórico; un ser viviente dotado de voluntad, acción y libertad que interactúa con su entorno y con los otros. La Vida y la vivencia trascienden así el mero ámbito subjetivo y se encaminan hacia la comprensión del hombre y de la historia.

Como se dijo, lo que caracteriza al mundo humano es el valor, el sentido y el significado. A él sólo se accede desde la vida anímica, desde la experiencia interna, este mundo es inaprensible para la experiencia externa de los fenómenos, por ello para Dilthey las ciencias naturales carecen de interioridad. Esta es la base en que se sustenta la diferencia establecida entre la comprensión y el conocimiento. Asimismo, las objetivaciones del espiritu no son sólo el resultado de la actividad del intelecto o razón sino también de flujo de sentimientos y voliciones. Por eso el estudio de estas objetivaciones del espiritu, de las realidades creadas por el hombre que constituyen el mundo histórico, requiere de una nueva fundamentación crítica. A ella apunta la filosofía de la experiencia que tal como la entiende Dilthey es Lebenserfabrung. Ésta es la sumatoria de la experiencia interna y la externa, ambas se integran gracias a su contacto íntimo con la vida; así Dilthey pretende eliminar el dilema dualista de lo interno y externo presentado en las filosofías de Comte y de Kant.

Cabe recordar que no existe en Dilthey la separación real entre materia (Stoff) y forma (Form) ${ }^{48}$, el objeto interno, del que da cuenta la experiencia interna no es una proyección de esquemas sobre una realidad ajena sino un modo intuitivo y de acceso inmediato, es la transferencia como totalidad. La separación es una actividad cognoscitiva a posteriori dada al

\section{${ }^{47}$ Ibidem, p. 178.}

${ }^{48} \mathrm{Al}$ respecto véase, Dilthey, W., "Estructura del mundo histórico por las ciencias del espíritu", en El mundo histórico, pp. 201-2 y 303-4; Dilthey, W., (1892), "Vida y conocimiento. Proyecto de lógica gnoseológica y teoría de las categorias", en: Dilthey, W., Crítica de la razón bistórica, Trad. Moya Espí, Barcelona, Península, 1986; y; Francisco Fernández Labastida, "Wilhelm Dilthey y las categorías de la vida: la metamorfosis historicista del apriorismo kantiano", en Anuario Filosófico, XXXVII/3 (2004), pp. 869-883. 
conceptualizar, al intentar reducir el mundo a concepto; actividad propia del hombre pero que la filosofía a lo largo de la historia ha olvidado y que proviene de una conexión originaria, imposible de abarcar completamente en conceptos. La vivencia total (Gesammterlebnis) es el carácter total del mundo, la crítica de la razón bistórica tiene como fundamento la filosofía de la vida; amplia el marco gnoseológico tanto del empirismo como del trascendentalismo, a uno critica su apelación ingenua a la experiencia y al otro su apoyo en el apriorismo ${ }^{49}$. Por ello, la filosofía diltheyana no es trascendental, no postula un a priori dado en la conciencia formal. Las facultades humanas -el conocer, el actuar libre de la voluntad y el sentirson históricas; por ello, toda fundamentación gnoseológica se apoya en la "experiencia total" o "experiencia de la vida" (Lebeserfabrung). Dilthey busca evitar así esa tendencia de la filosofía a reducir la pluralidad de la vida a un único elemento que le permita pensarla; evitar la violencia teórica de la filosofía que pretende dominar al mundo y no vivir en el mundo. Es decir, su fundamentación radica en la vida, "el pensamiento hace su aparición en el proceso de la vida; así, pues, en lo que refiere a su fundamentación, hay que remontarse hasta este último" 50 ; la realidad es el despliegue de la vida y la historia. Rechaza en tal sentido el empirismo por subordinarlo todo a la experiencia (Erfabrung) de base cientificista y a las filosofías de la representación por su sumisión a las proyecciones de una conciencia abstracta meramente formal. Si se ha de postular algún apriorismo en Dilthey, éste es la Vida; la Vida es, tal vez, su postulado metafísico-especulativo. La vida y la acción serían las condiciones históricas de posibilidad del hombre y permitirían a su vez la comprensión.

A modo de conclusión, el hombre es un ser histórico, un ser viviente, antes que un ser contemplativo, reflexivo. La psicología descriptiva tiene

49 Los axiomas de las ciencias naturales y la teoría a priori de Kant son conexiones racionales de lo dado en la conexión viva; pero esa conexión es vida con anterioridad al conocimiento (Cfr. Dilthey, W., "Ideas acerca de una psicología descriptiva y analítica", p. 243).

50 Cfr. Dilthey (1892), "Vida y conocimiento. Proyecto de lógica gnoseológica y teoría de las categorías", en Dilthey, W., Crítica de la razón bistórica, p. 181. 
como objeto este «hombre viviente como punto de cruce», busca fundamentar la experiencia integral y no la experiencia representativista de la conciencia. Dilthey pasa así del ámbito de una conciencia formal al mundo de la vida. El espíritu objetivo es el mundo al que atienda las ciencias del espíritu porque allí habita el hombre (espíritu subjetivo) como un "punto de cruce". El hombre no es un ser desanudado al que se lo podría comprender gracias a una contemplación interna -reflexión- ni tampoco un ser sometido al mundo que se lo lograría conocer gracias a la ley natural. Espíritu subjetivo y espíritu objetivo, el hombre, su interacción con otros hombres y las objetivaciones que produce constituyen en conjunto ese mundo del que da cuenta las ciencias del espíritu; por ello, no se puede hablar en Dilthey ni de un subjetivismo de tipo trascendental ni de un objetivismo de tipo positivista, sino de un intento de integración de ambas posiciones eliminando sus excesos: la caída en el solipsismo, por un lado, y en el determinismo por el otro.

Recibido: 11/2010; aprobado: 03/2011. 